\title{
Ocular antigens VIII: assay of delayed hypersensitivity to corneal epithelium in the rabbit
}

\author{
C. J. J. BRINKMAN, M. P. J. OERLEMANS-v. ZUTPHEN, AND \\ R. M. BROEKHUYSE
}

From the Institute of Ophthalmology, University of Nijmegen, The Netherlands

SUMMARY Rabbits were sensitised with complete bovine corneal epithelium. The lymphocyte stimulation test was performed with the lymphocytes of these rabbits using the soluble and sonicated insoluble fraction of the corneal epithelium as the antigens. A striking difference existed in the optimal test conditions for these antigen fractions.

By comparing the results of the lymphocyte stimulation test with other immunological parameters, namely, skin test reaction, antibody titre, and phytohaemagglutinin stimulation of the lymphocytes, we concluded that both antigen fractions stimulate predominantly the T-lymphocyte system, although boosting augmented the humoral immune response. Stimulation of the cultured lymphocytes by both the separate and mixed antigen fractions is evidence for the existence of crossreacting antigens between the soluble and insoluble epithelial fractions.

It is generally accepted that T-lymphocyte cytotoxicity is the principal effector of corneal graft rejection. By means of the leucocyte migration inhibition test as a detector of delayed hypersensitivity cellular immunity to corneal antigens has been established in several disorders of the cornea and after keratoplasty (Henley et al., 1971; Shore et al., 1972; Henley and Okas, 1974; Szabó et al., 1975). Moreover, it has been shown that antigens extracted from the whole cornea can elicit cellular immunity in guinea pigs (Ugrinski and Kirkpatrick, 1974).

Most of these studies were performed with soluble antigens extracted from the whole cornea. In addition to the intrinsic antigens of the cornea there are appreciable amounts of serum proteins especially localised in the stroma (Broekhuyse, 1972). These serum proteins, with the exception of an albumin-like protein, are absent in the epithelium of the cornea (Berger, 1969), which makes the epithelium suitable for a study of the immunological properties of corneal tissues. The possible role of the insoluble fraction of the corneal tissues, including cell membranes and connective tissue, needs further investigation. This fraction contains various antigens, including the membrane-associated histocompatibility antigens and structural glycoproteins. The latter appeared to display transplanta-

Address for reprints: Dr C. J. J. Brinkman, Institute of Ophthalmology, University of Nijmegen, Philips van Leydenlaan 15, Nijmegen, The Netherlands. tion antigen activity (Treffers and Broekhuyse, 1977). Whether sensitisation with xenogenic mixtures supplies adequate information about allogenic transplantation is doubtful, because this transplantation largely depends on histocompatibility antigens. We have, however, carried out such sensitisation in the present study as a preparatory investigation into the nature of the antigenicity of soluble and insoluble (membranous) epithelial constituents of the cornea.

After determining the optimal conditions for the lymphocyte stimulation test we compared the antigenicity of both the soluble and the particulate antigens of the corneal epithelium and correlated these results with other immunological parameters, namely, the antibody titre, the skin test, and phytohaemagglutinin stimulation.

\section{Material and methods}

ISOLATION OF THE EPITHELIAL ANTIGENS Fresh calf eyes were washed with saline, dipped in $0.25 \%$ chloramphenicol, and transported on ice to the laboratory. All further procedures were carried out at 0 to $4^{\circ} \mathrm{C}$ unless indicated otherwise. After rinsing the cornea with saline only the central part of the epithelium was scraped off to avoid contamination with other tissue. Homogenisation was carried out in a Potter-Elvehjem homogeniser in

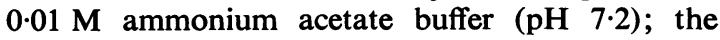


mixture was sonicated until a homogeneous suspension was obtained. For separating the soluble and insoluble fraction the homogenate was centrifuged at $15000 \mathrm{~g}$ for $30 \mathrm{~min}$. The supernatant was lyophilised, and the soluble epithelial fraction (EpSo) was stored at $-20^{\circ} \mathrm{C}$ until used. The sediment was washed once with $0.01 \mathrm{M}$ ammonium acetate buffer and several times with water. The sediment was then lyophilised and the product, the insoluble epithelial fraction (EpIn), was stored at $-20^{\circ} \mathrm{C}$ until used.

\section{SENSITISATION}

Seventeen adult New Zealand rabbits of both sexes were injected subcutaneously with sonicated complete epithelium $(100 \mathrm{mg}$ wet weight dispersed in $1 \mathrm{ml}$ phosphate buffered saline (PBS) and emulsified with $1 \mathrm{ml}$ complete Freund's adjuvant (FCA)). After 1 week 8 rabbits received another identically prepared injection subcutaneously in order to stimulate further antibody response. Three rabbits were injected subcutaneously with $15 \mathrm{mg}$ EpSo which had been solubilised in $1 \mathrm{ml}$ PBS and emulsified with $1 \mathrm{ml}$ FCA. Skin tests were carried out by injecting $0.05 \mathrm{ml}$ EpSo solution in PBS $(5 \mathrm{mg}$ dry weight per $\mathrm{ml}$ ). The reaction was recorded at 24 hours. Unsensitised rabbits were used as controls.

\section{LYMPHOCYTE CLLTURE}

Blood was withdrawn from: an ear vein or from the heart and defibrinated with glass beads. Lymphocytes were isolated from the diluted blood as described by Du Bois et al. (1973). 106 lymphocytes were suspended in $1 \mathrm{ml}$ Eagle's minimal essential medium (MEM) buffered with $0.025 \mathrm{M}$ Tris ( $\mathrm{pH}$ $7 \cdot 4$ ); this solution was supplemented with $100 \mathrm{U} / \mathrm{ml}$ penicillin, $100 \mu \mathrm{g} / \mathrm{ml}$ streptomycin, and $15 \%$ homologous inactivated rabbit serum. The lymphocytes were stimulated with $50 \mu \mathrm{g}$ PHA-P (Difco), and with varying amounts of EpSo and EpIn. The EpSo and EpIn solutions were sterilised by ultrasonic treatment. Sterility was checked by incubating EpSo and EpIn alone in the culture medium.

The cells stimulated with PHA-P were harvested after 50 hours and those stimulated with EpSo or EpIn as indicated below under 'Results'. Twentyfour hours before harvesting, $0.5 \mu \mathrm{Ci}{ }^{3} \mathrm{H}$-thymidine (Radiochemical Centre, Amersham, England; SA $23.3 \mathrm{Ci} / \mathrm{mmol}$ ) was added in $0.02 \mathrm{ml} \mathrm{MEM}$. The cells were collected on Millipore glass fibre filters and washed with saline. Radioactivity was determined by incubating the filters (after drying by heat) in $6 \mathrm{ml}$ scintillation fluid containing $100 \mathrm{mg}$ dimethyl-POPOP and $5 \mathrm{~g}$ PPO in 1 litre toluene. Counting was performed in an Isocap 300 scintillation counter (Nuclear Chicago). The results are reported as the stimulation index (SI), which is expressed as: $\mathrm{SI}=(\mathrm{cpm}$ of stimulated cells $) /(\mathrm{cpm}$ of unstimulated cells). A SI $\geqslant 2$ is considered to be positive.

\section{ANTIBODY TITRE}

The antibody titre was determinéd by the haemagglutination test as described by Herbert (1973) using $1 \mathrm{ml} \mathrm{2 \% (w/v)} \mathrm{tanned} \mathrm{erythrocytes} \mathrm{incubated}$ with $1 \mathrm{mg}$ antigen (Treffers and Broekhuyse, 1977).

\section{Results}

\section{CULTURE PERIOD}

Table 1 shows the results of ${ }^{3} \mathrm{H}$-thymidine incorporation into lymphocytes stimulated with $500 \mu \mathrm{g}$ EpSo and $250 \mu \mathrm{g}$ EpIn using different culture periods. Maximal stimulation indices were achieved between 4 and 6 days for EpSo and between 3 and 4 days for EpIn. A period of 5 days for EpSo and a period of 4 days for EpIn were used for further investigations.

\section{DOSE RESPONSE}

Table 2 shows the results of the ${ }^{3} \mathrm{H}$-thymidine incorporation into lymphocytes cultured in the presence of various amounts of EpSo and EpIn. Mean values of maximal stimulation indices by these fractions occurred at concentrations between $490 \mu \mathrm{g}$ and $780 \mu \mathrm{g}$ for EpSo, and between $50 \mu \mathrm{g}$ and $240 \mu \mathrm{g}$ for EpIn. For EpSo a concentration of $500 \mu \mathrm{g}$ and for EpIn a concentration of $100 \mu \mathrm{g}$ were considered to be optimal for further investigations.

Table $1 \quad 1 \times 10^{6}$ rabbit lymphocytes sensitised with complete corneal epithelium were stimulated with $500 \mu \mathrm{g}$ EpSo or $250 \mu \mathrm{g}$ EpIn during varying periods of culture. The average period yielding the maximal stimulation index is given

\begin{tabular}{ll}
\hline Average culture period (days) $\pm S D$ \\
\hline EpSo & EpIn \\
$5 \cdot 0 \pm 1 \cdot 0$ & $3 \cdot 7 \pm 0 \cdot 75$ \\
$(\mathrm{n}=9)$ & $(\mathrm{n}=7)$ \\
(range 4-6) & (range 3-5) \\
\hline
\end{tabular}

Table $21 \times 10^{6}$ rabbit lymphocytes sensitised with complete corneal epithelium were stimulated with various amounts of EpSo and EpIn for 5 days and 4 days respectively. Range of dry weight material giving the maximal stimulation index is given

\begin{tabular}{ll}
\hline Range of dry weight material $(\mu g)$ for maximal SI \\
\hline EpSo & EpIn \\
\hline $\begin{array}{l}490-780 \\
(\mathrm{n}=9)\end{array}$ & $50-240$ \\
$(\mathrm{n}=6)$
\end{tabular}


Table 3 Stimulation of corneal-epithelium-sensitised lymphocytes with EpSo ( 5 days' cultivation with $500 \mu g$ ), EpIn (4 days' cultivation with $100 \mu \mathrm{g}$ ), EpSo plus EpIn (4 days' cultivation with $500 \mu \mathrm{g}$ EpSo plus $100 \mu \mathrm{g}$ EpIn), and $P H A-P(50 h$ cultivation with $50 \mu \mathrm{g})$ is compared with the antibody titre of EpSo and EpIn and the skin test intensity recorded after $24 \mathrm{~h}(\mathrm{~mm})$. Stimulation is given as the stimulation index

\begin{tabular}{|c|c|c|c|c|c|c|c|}
\hline \multirow{2}{*}{ Rabbit no. } & \multicolumn{4}{|l|}{$S I$} & \multicolumn{2}{|c|}{ Antibody titre } & \multirow{2}{*}{$\frac{\text { Skin reaction }}{\text { EpSo }(\phi \text { in } \mathrm{mm})^{*}}$} \\
\hline & EpSo & EpIn & $E p S o \div E p I n$ & $P H A-P$ & EpSo & EpIn & \\
\hline 8677 & $75 \cdot 3$ & $61 \cdot 9$ & $73 \cdot 9$ & $82 \cdot 9$ & 2000 & 4000 & 17 \\
\hline 8678 & $19 \cdot 4$ & $15 \cdot 0$ & $15 \cdot 6$ & $30 \cdot 2$ & 500 & 100 & 17 \\
\hline 8679 & $65 \cdot 7$ & $20 \cdot 7$ & $22 \cdot 5$ & $48 \cdot 6$ & 1000 & 2000 & 28 \\
\hline 8680 & $81 \cdot 6$ & $23 \cdot 9$ & $38 \cdot 9$ & $152 \cdot 2$ & 2000 & 4000 & 26 \\
\hline 8681 & $43 \cdot 9$ & $24 \cdot 3$ & $37 \cdot 5$ & $251 \cdot 9$ & 4000 & 4000 & 20 \\
\hline 8683 & $68 \cdot 0$ & $28 \cdot 0$ & $18 \cdot 0$ & $46 \cdot 2$ & 1000 & 500 & 20 \\
\hline 8684 & $44 \cdot 0$ & $15 \cdot 3$ & $36 \cdot 4$ & $45 \cdot 1$ & 2000 & 4000 & 20 \\
\hline 8685 & $69 \cdot 7$ & $28 \cdot 5$ & $34 \cdot 5$ & $52 \cdot 8$ & 4000 & 8000 & 26 \\
\hline 8686 & $16 \cdot 8$ & $16 \cdot 3$ & $18 \cdot 1$ & 73.9 & 2000 & 2000 & 25 \\
\hline Mean & $53 \cdot 8$ & $26 \cdot 0$ & $32 \cdot 8$ & $87 \cdot 1$ & 2000 & 3000 & 22 \\
\hline
\end{tabular}

* $\phi$ represents diameter of erythema.

Table 4 As Table 3. The rabbits received a second dose of antigen emulsified in FCA 1 week after first injection

\begin{tabular}{|c|c|c|c|c|c|c|c|}
\hline \multirow{2}{*}{ Rabbit no. } & \multicolumn{4}{|l|}{$S I$} & \multicolumn{2}{|c|}{ Antibody titre } & \multirow{2}{*}{$\frac{\text { Skin reaction }}{\text { EpSo }(\phi \text { in } m m)^{*}}$} \\
\hline & $\overline{E p S o}$ & EpIn & $E p S o+E p I n$ & $P H A-P$ & EpSo & EpIn & \\
\hline 8 & $4 \cdot 5$ & $1 \cdot 1$ & $2 \cdot 6$ & $6 \cdot 7$ & 8000 & 16000 & 9 \\
\hline 9 & ND & ND & ND & $23 \cdot 4$ & 2000 & 8000 & 12 \\
\hline 10 & $10 \cdot 8$ & $3 \cdot 8$ & $5 \cdot 5$ & $50 \cdot 6$ & 4000 & 8000 & 10 \\
\hline 11 & $11 \cdot 1$ & $6 \cdot 0$ & $7 \cdot 9$ & $9 \cdot 3$ & 8000 & 8000 & 20 \\
\hline 13 & $43 \cdot 3$ & $10 \cdot 2$ & ND & $60 \cdot 4$ & 8000 & 4000 & 18 \\
\hline 14 & $81 \cdot 8$ & $9 \cdot 2$ & ND & $45 \cdot 1$ & 8000 & 16000 & 19 \\
\hline 15 & ND & ND & ND & $38 \cdot 2$ & 4000 & 8000 & 18 \\
\hline 16 & $17 \cdot 6$ & $12 \cdot 2$ & ND & $4 \cdot 8$ & 4000 & 8000 & 21 \\
\hline Mean & $28 \cdot 2$ & $7 \cdot 1$ & - & $29 \cdot 8$ & 6000 & 9500 & 16 \\
\hline
\end{tabular}

* $\phi$ represents diameter of erythema. ND $=$ not done.

STIMULATION UNDER OPTIMAL CONDITIONS Table 3 gives the results of experiments in which the lymphocytes from corneal-epithelium-sensitised rabbits were tested under optimal conditions. A high SI found with EpSo, EpIn, and PHA-P and an intense skin reaction were accompanied by a low antibody production. The data in Table 4 are from rabbits which had received a second antigen injection 1 week after the first. These rabbits had on the average an antibody titre three times higher than those of Table 3 ( $P<0.01$; Mann-Whitney $U$ test $)$. This high antibody titre was accompanied by a less intense skin reaction $(\mathrm{P}<0.05)$ and a much lower SI with EpSo $(\mathbf{P}<0.09)$, EpIn $(\mathbf{P}<0.0005)$, and
PHA-P $(\mathbf{P}<0.02)$ than the rabbits shown in Table 3. Statistical analysis of the ratios of SI (EpSo)/antibody titre (EpSo), SI (EpIn)/antibody titre (EpIn), and skin reaction (EpSo)/antibody titre (EpSo) in Tables 3 and 4 revealed highly significant differences ( $\mathrm{P}<0.0009, \mathrm{P}<0.0005$, and $\mathrm{P}<0.0005$, respectively).

The lymphocytes of normal rabbits could not be stimulated by EpIn (SI $=1 \cdot 0 \pm 0 \cdot 1 ; n=4)$ and sometimes weakly by EpSo $(\mathrm{SI}==1 \cdot 5=1 \cdot 2) ; \mathrm{n}=6)$. The SI of normal rabbit lymphocytes cultured in the presence of $50 \mu \mathrm{g}$ PHA-P for 50 hours (optimal circumstances) amounted to $44 \cdot 0 \pm 16 \cdot 5 \quad(n=10)$. Normal rabbits showed negative skin reactions to EpSo and negative antibody titres to EpSo and EpIn. 
Because Tables 3 and 4 show that stimulation of the lymphocytes with EpSo plus EpIn never exceeds the stimulation with EpSo added separately, we investigated the possibility of common antigens in both fractions. Table 5 shows that lymphocytes sensitised to EpSo are also stimulated by the EpIn fraction, which means that both fractions contain cross-reacting or possibly identical antigens.

\section{Discussion}

This investigation shows that it is possible to stimulate corneal-epithelium-sensitised lymphocytes with ultrasonically dispersed cell membranes isolated from the corneal epithelium. The particles obtained are vesicles consisting of membrane lipids and proteins. The amount of stimulation with the insoluble epithelial fraction was always less than with the soluble epithelial fraction when both were measured under optimal circumstances. Two explanations are possible for this phenomenon. It is possible that antigens hidden in the vesicle membrane or included in the vesicle lumen cannot reach the receptor of the lymphocyte membrane and therefore cannot trigger the stimulation. Another possibility is the limited variability of the antigens in the insoluble fraction as contrasted with the soluble fraction.

If EpSo and EpIn stimulated different lymphocyte populations, one would expect that incubation of the lymphocytes with EpSo plus EpIn would give additive stimulation indices. From the finding that stimulation of the lymphocytes with EpSo plus EpIn never exceeds the stimulation found by EpSo alone (Tables 3 and 4) we believe that the antigens of the EpIn fraction stimulate the same lymphocyte population as some or all antigens of the EpSo fraction. This suggests that both epithelial fractions possess common antigenicity. This is confirmed by the fact that EpSo-sensitised lymphocytes are also stimulated after incubation with the EpIn fraction (Table 5). The seemingly suppressive effect of EpIn on the SI of EpSo is caused by a suboptimal incubation period for EpSo of 4 days.

The present study shows the importance of having correct conditions for the lymphocyte stimulation

Table 5 Stimulation indices of EpSo-sensitised lymphocytes after incubation with EpSo and EpIn under optimal circumstances

\begin{tabular}{lrl}
\hline \multirow{2}{*}{ Rabbit no. } & \multicolumn{2}{l}{ SI } \\
\cline { 2 - 3 } & EpSo & EpIn \\
\hline 34 & $53 \cdot 0$ & $17 \cdot 3$ \\
35 & $144 \cdot 1$ & $44 \cdot 7$ \\
36 & $53 \cdot 3$ & $19 \cdot 7$ \\
\hline
\end{tabular}

test. These conditions have to be determined accurately before any conclusion from the outcome of the test can be made. This is especially true for clinical application because the degree of stimulation may be very low. The lack of optimal conditions when using human lymphocytes for detecting cellular immunity in ocular diseases may be one of the causes of the discrepancies found among the tests of various authors (Henley et al., 1971; Shore et al., 1972; Henley and Okas, 1974; Szabo et al., 1975; Freedman and Smit, 1974; Hammer, 1971; Hammer and Olah, 1975; Wong et al., 1971).

Another possibility for low or negative results in the lymphocyte stimulation test may be the type of antigen. In this report it is shown that the insoluble epithelial fraction can elicit cellular immunity in rabbits. Marak et al. (1971) did not find stimulation of lymphocytes from patients with uveitis on incubation with sedimented antigens from several parts of the eye; nevertheless, they suggested that the major part of the active antigens was present in the insoluble fraction even though they were unable to demonstrate these antigens. Antibodies to the HL-A antigens can be provoked in keratoplasty patients, which demonstrates the antigenic properties of this insoluble part of the membrane (Stark et al., 1973).

The lymphocyte stimulation test is believed to be an accurate test for detecting delayed-type hypersensitivity. However, we must be aware of the possible stimulation of B-lymphocytes in addition to or instead of T-lymphocytes (Greaves et al., 1974). From Tables 3 and 4 it appears that a high lymphocyte stimulation index and an intense skin reaction correlate with a low antibody titre. The converse is also true. This is in agreement with the results of Jevitz and Ekstedt (1971), who showed that, when cultured in vitro, lymphocytes of rabbits favouring delayed hypersensitivity provoked a greater response to antigen than the B-lymphocytes. It also appears that a high stimulation found with PHA-P correlated with a relatively high stimulation with EpSo and EpIn and a more intense skin reaction. The transformation of lymphocytes by PHA is now well recognised as a measure of Tlymphocyte function; this also points to a dominating stimulation of the T-lymphocyte by EpSo and EpIn. From this point of view one could imagine that the activity of the T-lymphocytes could be triggered by the soluble antigens. This could be followed by graft rejection as a result of increasing cytotoxity of the T-lymphocytes by recognising the cross-reacting insoluble antigens.

We gratefully acknowledge the invaluable technical assistance provided by $\mathrm{Mr} \mathrm{H}$. Winkens and $\mathrm{Mr}$ J. W. Reitsma. 


\section{References}

Berger, B. (1969). Agarose gel electrophoresis of proteins from bovine corneal epithelium. Acta Ophthalmologica, 47, 1026-1040.

Broekhuyse, R. M. (1972). Ocular antigens II. Immunogenic factors in corneal stroma. Ophthalmologica, 165, 523-528.

Du Bois, M. J. G. J., Huismans, D. R., Schellekens, P. Th. A., and Eysvogel, V. P. (1973). Investigation and standardization of the conditions of micro-lymphocyte cultures, Tissue Antigens, 3, 402-409.

Freedman, J., and Smit, J. A. (1974). Lymphocyte transformation in Bantu-speaking negroes with endogenous uveitis. American Journal of Ophthalmology, 78, 45-48.

Greaves, M. F., Owen, J. J. T., and Raff, M. C. (1974). $\mathrm{T}$ - and B-lymphocytes: origins and properties and roles in immune responses, p. 93. Excerpta Medica. Elsevier: Amsterdam.

Hammer, H. (1971). Lymphocyte transformation test in sympathetic ophthalmitis and the Vogt-Koyanagi-Harada syndrome. British Journal of Ophthalmology, 55, 850-852.

Hammer, H., and Olah, M. (1975). Hypersensitivity towards alpha-crystalline in the heterochromia syndrome. Albrecht v. Graefes Archiv für Ophthalmologie, 197, 61-66.

Henley, W. L., and Okas, S. (1974). The study of ophthalmologic disease by leucocyte migration inhibition. Journal of Pediatric Ophthalmology, 11, 55-58.

Henley, W. L., Shore, B., and Leopold, I. H. (1971). Inhibition of leucocyte migration by corneal antigen in chronic viral keratitis. Nature New Biology, 233, 115.

Herbert, W. J. (1973). Passive haemagglutination with special reference to the tanned cell technique. Handbook of Experimental Immunology, ed. D. M. Weir, 2nd edn., pp. 20.1-20.20. Blackwell Scientific Publications: Oxford.

Jevitz, M. A., and Ekstedt, R. D. (1971). Correlation of lymphocyte transformation with the in vivo immune responsiveness of rabbits. Journal of Immunology, 106, 494-505.

Marak, G. E., Font, R. L., Johnson, M. C., and Alepa, F. P. (1971). Lymphocyte-stimulating activity of ocular tissues in sympathetic ophthalmia. Investigative Ophthalmology, 10, 770-774.

Shore, B., Leopold, I. H., and Henley, W. L. (1972). Cellular immunity in chronic ophthalmic disorders. American Journal of Ophthalmology, 73, 62-67.

Stark, W. J., Opelz, G., Newsome, D., Brown, R., Yankee, R., and Terasaki, P. I. (1973). Sensitization to human lymphocyte antigens by corneal transplantation. Investigative Ophthalmology, 12, 639-645.

Szabó, G., Balázs, Cs., Leövey, A., and Alberth, B. (1975). Immunological investigations of patients with transplanted cornea. Albrecht v. Graefes Archiv für Ophthalmologie, 196, 169-179.

Treffers, W. F., and Broekhuyse, R. M. (1977). Ocular antigens VII. The influence of Freund's complete adjuvant and corneal structure glycoprotein in xenogeneic keratoplasty. Experimental Eye Research, 25, 289-295.

Ugrinski, P. S., and Kirkpatrick, C. H. (1974). Corneal cellular immunity in the guinea-pig. American Journal of Pathology, 74, 365-376.

Wong, V. G., Anderson, R., and O'Brien, P. J. (1971). Sympathetic ophthalmia and lymphocyte transformation. American Journal of Ophthalmology, 72, 960-966. 